\title{
Invasive Pneumococcal Disease: Still Lots to Learn and a Need for Standardized Data Collection Instruments
}

\author{
T. J. Marrie, ${ }^{1}$ G. J. Tyrrell, ${ }^{2}$ Sumit R. Majumdar, ${ }^{3}$ and Dean T. Eurich ${ }^{4}$ \\ ${ }^{1}$ Department of Medicine, Dalhousie University, Halifax, NS, Canada \\ ${ }^{2}$ The Division of Diagnostic and Applied Microbiology, Department of Laboratory Medicine and Pathology, \\ University of Alberta and The Provincial Laboratory for Public Health, Edmonton, AB, Canada \\ ${ }^{3}$ Department of Medicine, Faculty of Medicine and Dentistry, University of Alberta, Edmonton, AB, Canada \\ ${ }^{4}$ School of Public Health, University of Alberta, Edmonton, AB, Canada \\ Correspondence should be addressed to T. J. Marrie; t.marrie@dal.ca
}

Received 6 January 2017; Revised 23 February 2017; Accepted 5 March 2017; Published 23 March 2017

Academic Editor: R. Andrew Mcivor

Copyright (C) 2017 T. J. Marrie et al. This is an open access article distributed under the Creative Commons Attribution License, which permits unrestricted use, distribution, and reproduction in any medium, provided the original work is properly cited.

\begin{abstract}
Background. Large studies of invasive pneumococcal disease (IPD) are frequently lacking detailed clinical information. Methods. A population-based 15-year study of IPD in Northern Alberta. Results. 2435 patients with a mean age of 54.2 years formed the study group. Males outnumbered females and Aboriginal and homeless persons were overrepresented. High rates of smoking, excessive alcohol use, and illicit drug use were seen. Almost all (87\%) had a major comorbidity and $15 \%$ had functional limitations prior to admission. Bacteremia, pneumonia, and meningitis were the most common major manifestations of IPD. Almost half of the patients had alteration of mental status at the time of admission and $22 \%$ required mechanical ventilation. Myocardial infarction, pulmonary embolism, and new onset stroke occurred in 1.7, 1.3, and 1.1\% of the patients, respectively; of those who had echocardiograms, $35 \%$ had impaired ventricular function. The overall in-hospital mortality was $15.6 \%$. Conclusions. IPD remains a serious infection in adults. In addition to immunization, preventative measures need to consider the sociodemographic features more carefully. A standard set of data need to be collected so that comparisons can be made from study to study. Future investigations should target cardiac function and pulmonary embolism prevention in this population.
\end{abstract}

\section{Introduction}

Streptococcus pneumoniae from the time of its discovery by Louis Pasteur in 1881 to the present day has been an important human pathogen [1]. The capsule of the pneumococcus, composed of polysaccharides, helps it avoid host defenses and hence it is a major virulence factor [2]. Challenges in finding an effective vaccine have been the number of capsular types (of which there are currently 94) and the fact that polysaccharides are not very antigenic [3]. Fortunately most of the cases of pneumococcal disease are caused by a smaller number of capsular serotypes and conjugating the polysaccharide with a protein has led to more effective vaccines [3].

There have been numerous prior studies of invasive pneumococcal disease (IPD) ranging from those with small numbers that are rich in clinical detail to those that are very large and are focused on the intended and unintended consequences of vaccination but lack necessary clinical details [47]. We, however, took advantage of the fact that pneumococcal protein conjugate vaccine seven (PCV-7) was introduced in Alberta, Canada, in 2002 and PCV-13 in 2010 to conduct a study of "IPD" in Northern Alberta. We specifically undertook a comprehensive and population-based study from 2000 to 2014 to provide a detailed description of invasive pneumococcal disease in a modern era. We feel this is of utmost importance as it will serve as bench mark for other studies.

\section{Methods}

2.1. Definitions. Cases of IPD were defined as per the national case definition of isolation of $S$. pneumoniae from a normally sterile site such as blood, CSF, pleural fluid, biopsy tissue, 
TABLE 1: Sociodemographic and lifestyle features in 2435 adults with invasive pneumococcal disease.

\begin{tabular}{|c|c|c|}
\hline & Number & Percent \\
\hline Number studied & 2435 & 100 \\
\hline Number of males & 1380 & 56.7 \\
\hline Mean age (SD) & $54.2(17.8)$ & \\
\hline Aboriginal (first nations) & 312 & 12.8 \\
\hline To hospital by ambulance & 1098 & 45.1 \\
\hline \multicolumn{3}{|l|}{ Admission status } \\
\hline Never seen at a hospital & 3 & 0.1 \\
\hline Outpatient only with visits for IV antibiotics & 10 & 0.4 \\
\hline Emergency Room only & 229 & 9.4 \\
\hline Inpatient & 2193 & 90.1 \\
\hline \multicolumn{3}{|l|}{ Residence prior to admission } \\
\hline Home & 1960 & 80.5 \\
\hline Homeless, no shelter & 98 & 4.0 \\
\hline Homeless, shelter & 86 & 3.5 \\
\hline Lodge/group home & 119 & 4.9 \\
\hline Continuing care facility & 60 & 2.5 \\
\hline Subacute care & 7 & 0.3 \\
\hline \multicolumn{3}{|l|}{ Functional status in the week prior to admission } \\
\hline Fully functional & 2078 & 85.4 \\
\hline Walking with assistance & 302 & 12.4 \\
\hline Wheelchair & 37 & 1.5 \\
\hline Bedridden & 18 & 0.7 \\
\hline Smoker, current & 1104 & 45.3 \\
\hline Alcohol, excess use & 620 & 25.5 \\
\hline Illicit drug use & 482 & 19.8 \\
\hline
\end{tabular}

joint aspiration, pericardial fluid, or peritoneal fluid [8]. IPD is a provincially notifiable disease in Alberta; therefore all invasive pneumococcal isolates are submitted to the Provincial Laboratory for Public Health (PLPH) for further characterization. This allowed us to prospectively identify all cases of IPD in Northern Alberta.

2.2. Clinical Data Collection. Research nurses collected sociodemographic, clinical, functional, and laboratory data using a standardized case report form (CRF). The research nurses received training on data collection prior to the start of the study. In addition to the CRF, standard operating procedures documents, definitions, drug classification, and underlying illness categorization were part of their working documents. With respect to underlying illnesses, if the attending physician recorded such an illness it was accepted as such. From September 2012 through the end of the study December 31, 2014, additional data were collected for a substudy examining cardiac events during the hospital stay. Our study received approval from the institutional research review committees of the Alberta Health Regions as well as the University of Alberta ethics review board.

2.3. Identification and Serotyping of S. pneumoniae Isolates. Streptococcus pneumoniae isolates were received at the Provincial Laboratory of Public Health from diagnostic laboratories in Alberta as per requirements of provincial notifiable disease regulations. The isolates were confirmed as $S$. pneumoniae based on characteristic morphology and optochin susceptibility [9]. All pneumococcal isolates that exhibited a positive Quellung reaction using commercial type specific antisera obtained from Statens Serum Institute, Copenhagen, Denmark, were assigned a serotype designation. Strains that were susceptible to optochin but which failed to serotype using the Quellung assay were assayed further using AccuProbe ${ }^{\mathrm{TM}}$ Streptococcus pneumoniae culture identification test, Gen-Probe, San Diego, CA, to confirm the species identification.

2.4. Comparison with Alberta Population. For comparison purposes some characteristics of the Alberta population were obtained from the Alberta Ministry of Health interactive website [10]. The representation of various occupations constituting the work force in Alberta was from [11].

\section{Results}

Two thousand four hundred and thirty-five patients with a mean age of 54.2 years had IPD over the 15 years of the study. Across all age groups, males were more likely to have IPD than females. Other sociodemographic features of the study population are given in Table 1 . Noteworthy is that $7.5 \%$ were homeless and $15 \%$ had some functional limitations in the weeks prior to presentation. The occupations of those 
TABLE 2: Occupations of 581 patients with IPD compared with Alberta population 2015 working in these occupations.

\begin{tabular}{|c|c|c|c|}
\hline \multirow{2}{*}{ Occupation } & \multicolumn{2}{|c|}{ IPD } & \multirow{2}{*}{$\begin{array}{c}\text { Alberta population, } \\
\%\end{array}$} \\
\hline & Number & $\%$ & \\
\hline Accommodation, food services & 37 & 6.3 & 6.5 \\
\hline Agriculture & 22 & 3.7 & 2.2 \\
\hline Business & 17 & 2.9 & 3.4 \\
\hline Construction & 147 & 25.3 & 11.0 \\
\hline Education & 35 & 6.0 & 6.7 \\
\hline Finance, real estate & 79 & 13.5 & 4.4 \\
\hline Forestry, mining, oil, and gas & 44 & 7.5 & 6.4 \\
\hline Health care & 20 & 3.4 & 11.7 \\
\hline Professional, science, teacher & 15 & 2.4 & 7.8 \\
\hline Transportation & 30 & 5.1 & 5.9 \\
\hline Utilities & 3 & 0.5 & 0.7 \\
\hline
\end{tabular}

who were working are presented in Table 2. For the most part these are similar to the Alberta population. Construction work is overrepresented and $36 \%$ of this group were welders. Teachers and health care workers were not at greater risk than the general population.

Comorbid illnesses were common, being present in 98.9\% (Table 3). If all cardiovascular conditions are combined, then, fully $45 \%$ of the study population were affected prior to presentation. Individually and apart from hypertension, COPD, recent cancer, and hepatitis $\mathrm{C}$ were most common.

The manifestations of IPD are presented in Table 4. Bacteremia and pneumonia were most common and the pneumonia patients by definition were bacteremic. Otherwise, meningitis was the most common manifestation of IPD $(4.9 \%)$ while endocarditis/pericarditis were least common $(<1 \%)$.

The complications and outcomes from IPD are shown in Table 5. Almost half the patients had altered mental status at the time of admission. Most (748/1039 [72\%]) patients with altered mental status had a Glasgow Coma Score value recorded: only $7.5 \%$ had a score of 15 while $40.6 \%$ had a value of 10 or less with 200 having a score of 3. Onequarter of patients were admitted to ICU and $88.5 \%$ of these patients required mechanical ventilation. Most of the acute complications occurred on hospital day 1 including admission to ICU, 557/618 (90\%); peritonitis, 33/39 (84\%); cardiac arrest, 51/70 (73\%); liver failure, 36/62 (58\%); heart failure, 51/90 (57\%); myocardial infarction, 44/78 (56\%); renal failure requiring dialysis, $47 / 99(47 \%)$.

The substudy $(N=811)$ related to cardiovascular complications is presented in Table 6. The most common complication was atrial fibrillation, which occurred in more than one in ten patients. What was surprising was that $24 \%$ had echocardiograms done, $87 \%$ of which were transthoracic, and $8.9 \%$ had severely impaired left ventricular function with ejection fractions $<30-35 \%$.

Table 7 shows the serotypes in PCV-7, PCV-13, and PPV-23 vaccines. These accounted for $22.7 \%, 52.3 \%$, and
TABLE 3: Comorbid illnesses in 2435 patients with invasive pneumococcal disease.

\begin{tabular}{lcc}
\hline & Number & Percent \\
\hline Any underlying disease & 2409 & 98.9 \\
Selected underlying diseases & & \\
Epilepsy & 136 & 5.6 \\
Alzheimer's disease & 83 & 3.4 \\
Stroke & 106 & 4.4 \\
Hypertension & 622 & 25.5 \\
Heart failure & 156 & 6.4 \\
Previous myocardial infarction & 168 & 6.9 \\
Atrial fibrillation & 128 & 5.3 \\
Anemia & 167 & 6.9 \\
Insulin dependent diabetes mellitus & 87 & 3.6 \\
Hepatitis C & 307 & 12.6 \\
Cirrhosis & 151 & 6.2 \\
HIV/AIDS & 117 & 4.8 \\
Asplenia & 37 & 1.5 \\
Rheumatoid arthritis & 56 & 2.3 \\
Asthma & 266 & 10.9 \\
Chronic obstructive pulmonary disease & 441 & 18.6 \\
Cancer within thepast 5 years & 307 & 12.6 \\
Lung cancer & 53 & 2.1 \\
Multiple myeloma & 42 & 1.7 \\
Chronic lymphocytic leukemia & 19 & 0.7 \\
Lymphoma & 17 & 0.7 \\
Acute leukemia & 5 & 0.2 \\
Solid organ transplant & 14 & 0.6 \\
No underlying disease & 26 & 1.1 \\
One underlying disease & 32 & 87.1 \\
Two underlying diseases & 10.5 \\
Three underlying diseases & 1.3 \\
\hline
\end{tabular}

TABLE 4: Manifestations of invasive pneumococcal disease among 2435 patients.

\begin{tabular}{lcc}
\hline Manifestation & Number & Percent \\
\hline Bacteremia & 2325 & 95.5 \\
Bacteremia source unknown & 316 & 12.9 \\
Pneumonia & 2009 & 82.2 \\
Meningitis & 120 & 4.9 \\
Cellulitis & 65 & 2.7 \\
Sinusitis & 44 & 1.8 \\
Septic arthritis & 40 & 1.6 \\
Peritonitis & 39 & 1.6 \\
Otitis media & 38 & 1.6 \\
Endocarditis & 26 & 1.0 \\
Pericarditis & 20 & 0.8 \\
\hline
\end{tabular}

$82.9 \%$ of isolates, respectively. An additional five serotypes rounded out those that accounted for $1 \%$ or more of the isolates but were not present in the first 23 serotypes listed. Overall these 28 serotypes accounted for $90.3 \%$ of the isolates. 
TABLE 5: Complications/outcomes of invasive pneumococcal disease among 2435 patients.

\begin{tabular}{|c|c|c|}
\hline Complication & Number & Percent \\
\hline Altered mental status & 1039 & 42.7 \\
\hline Intensive care admission & 618 & 25.4 \\
\hline \multicolumn{3}{|l|}{ Respiratory failure requiring } \\
\hline Mechanical ventilation & 547 & 22.5 \\
\hline Pleural effusion & 846 & 34.7 \\
\hline Chest tube & 255 & 10.5 \\
\hline Aspiration & 179 & 7.4 \\
\hline Empyema & 175 & 7.2 \\
\hline Renal failure requiring dialysis & 99 & 4.1 \\
\hline Congestive heart failure & 90 & 3.7 \\
\hline Myocardial infarction & 78 & 3.2 \\
\hline Cardiac arrest & 70 & 2.8 \\
\hline New onset seizures & 67 & 2.8 \\
\hline Upper GI bleed & 64 & 2.6 \\
\hline Liver failure & 62 & 2.5 \\
\hline Lower GI bleed & 31 & 1.2 \\
\hline New onset stroke & 28 & 1.1 \\
\hline Pulmonary embolus & 11 & 1.3 \\
\hline Died (in hospital) & 379 & 15.6 \\
\hline Transferred to another acute care facility after admission & 275 & 11.6 \\
\hline Remained in acute care facility after infection cured & 149 & 6.1 \\
\hline Discharged home on antibiotics & 1370 & 56.3 \\
\hline Home care following discharge & 288 & 11.8 \\
\hline
\end{tabular}

An additional 31 serotypes were represented among the remaining $11.5 \%$ of the isolates.

\section{Discussion}

The percentage of males with IPD at $56.7 \%$ was higher than the percentage of females. Despite the introduction of pneumococcal conjugate vaccines the rate of IPD among males remains higher than that among females especially in children and in adults aged $40-64$ and $>74$ years [12]. Most of the patients with IPD had pneumonia and in studies of pneumonia in general males tend to be predominate [13].

People of Aboriginal descent were overrepresented in this study population at $12.8 \%$ whereas they constitute about $5.2 \%$ of the population of Alberta [10]. It has been noted that among resource poor populations a gap in rates of IPD remains compared with other populations in the same geographic area, a gap that will not be solved by vaccination alone $[13,14]$.

Almost half the patients with IPD required an ambulance to come to hospital. This is similar to what is observed at a tertiary care hospital in Halifax where $45 \%$ of the patients with all-cause pneumonia arrive by ambulance (Petrie D, personal communication). However $90 \%$ of our patients were admitted to hospital in sharp contrast to the rate of $47 \%$ admission rate for all-cause pneumonia in the Edmonton area but not surprising since most of these patients were bacteremic [15]. The $90 \%$ admission rate for patients with IPD
TABLE 6: Cardiac events and investigations 871 patients with IPD.

\begin{tabular}{lcc}
\hline Event or investigation & Number & Percent \\
\hline Atrial fibrillation & 109 & 12.5 \\
Myocardial infarction & 15 & 1.7 \\
Asystole & 13 & 1.5 \\
Ventricular tachycardia $>30 \mathrm{sec}$ & 5 & 0.5 \\
\hline Cardiology consultation & 60 & 6.8 \\
Coronary angiogram & 9 & 1 \\
Echocardiogram & 210 & 24.1 \\
Tricuspid regurgitation & 114 & 54.3 \\
Mitral regurgitation & 112 & 53.3 \\
Aortic regurgitation & 25 & 11.9 \\
Valve vegetation & 5 & 2.3 \\
Ejection fraction & & \\
$\geq 50 \%$ & 170 & 80.7 \\
$40-45 \%$ & 23 & 10.9 \\
$30-35 \%$ & 6 & 2.8 \\
$20-25 \%$ & 5 & 2.3 \\
$<20 \%$ & 8 & 3.8 \\
\hline
\end{tabular}

is similar to that seen in the USA at $93 \%$ prior to introduction of PCV-13 and 95\% afterwards [16] but is higher than the $66.9 \%$ admission rate among adults of 65 years of age and over with IPD in Ontario [17]. 
TABle 7: Selected Streptococcus pneumoniae serotypes from 2401 patients (data missing for 34 patients due to nonviable isolates).

\begin{tabular}{|c|c|c|}
\hline Serotype & Number & Percent \\
\hline 1 & 28 & 1.1 \\
\hline 3 & 161 & 6.6 \\
\hline $4^{*}$ & 219 & 9.0 \\
\hline 5 & 242 & 9.9 \\
\hline $6 \mathrm{~A}$ & 51 & 2.1 \\
\hline $6 B^{*}$ & 42 & 1.7 \\
\hline $7 F$ & 129 & 5.3 \\
\hline $9 \mathrm{~V}^{*}$ & 64 & 2.6 \\
\hline $14^{*}$ & 92 & 3.8 \\
\hline $18 C^{*}$ & 39 & 1.6 \\
\hline $19 \mathrm{~A}$ & 113 & 4.6 \\
\hline $19 \mathrm{~F}^{*}$ & 53 & 2.2 \\
\hline $23 \mathrm{~F}^{*}$ & 45 & 1.8 \\
\hline 2 & 1 & 0.04 \\
\hline 8 & 193 & 7.9 \\
\hline $9 \mathrm{~N}$ & 65 & 2.7 \\
\hline $10 \mathrm{~A}$ & 17 & 0.7 \\
\hline $11 \mathrm{~A}$ & 80 & 3.3 \\
\hline $12 \mathrm{~F}$ & 70 & 2.9 \\
\hline 15B & 15 & 0.6 \\
\hline $17 \mathrm{~F}$ & 27 & 1.1 \\
\hline 20 & 93 & 3.8 \\
\hline $22 \mathrm{~F}$ & 176 & 7.2 \\
\hline $32 \mathrm{~F}$ & 0 & 0 \\
\hline $33 \mathrm{~F}$ & 45 & 1.8 \\
\hline $16 \mathrm{~F}$ & 33 & 1.4 \\
\hline $23 \mathrm{~A}$ & 39 & 1.6 \\
\hline $23 \mathrm{~B}$ & 30 & 1.2 \\
\hline $16 \mathrm{~F}$ & 33 & 1.4 \\
\hline
\end{tabular}

The first 13 serotypes are in PCV-13 and first 23 in PPV-23. * denotes serotypes in PCV-7. The final four serotypes represent the remaining serotypes that accounted for $\geq 1 \%$ of the isolates beyond those in the 23 -valent vaccine.

Residence at the time of admission may have implications for programs directed towards prevention of IPD in adults. Only $80 \%$ of our patients were living at home whereas $7.5 \%$ were homeless and $7.4 \%$ were in a group home setting. The rate of homelessness among patients with IPD is much higher than the $2.5 \%$ observed for patients with all-cause community-acquired pneumonia in the Edmonton area [18]. This overrepresentation of homeless persons among those with IPD is likely due to the very high rate of IPD in this population. Pleveneshi et al. found that the rate of IPD among homeless persons in Toronto was $273 / 100,000$ per year compared with $9 / 100,000$ per year in the general adult population [19]. One of the reasons for this high rate is crowding in homeless shelters resulting in high transmission rates of pneumococcal disease [20]. During the course of this study an outbreak of serotype 5 accounted for about a quarter of all cases and homelessness was a risk factor for transmission of serotype 5 in this outbreak [21]. The high rates of tobacco smoking and alcohol abuse in this population also contribute to the higher rates of IPD [19]. Further study is needed to determine what contribution each of these factors, homelessness, tobacco, and alcohol usage, makes to the increased risk of IPD in this population. Vaccination and other intervention programs should have a high benefit in this population.

In terms of common lifestyle risk factors for IPD, almost half of the patients in our cohort were tobacco smokers. This contrasts with $28.3 \%$ of those with all-cause pneumonia in Edmonton requiring hospitalization and with a $28 \%$ smoking rate in the general population of Alberta [18, 22]. Smoking is a well-known risk factor for IPD with odds ratio of 4.1 when compared with those without IPD [23]. There is a doseresponse relationship with the number of cigarettes smoked per day and those exposed to second-hand smoke are also affected [23]. Furthermore, 25\% of our patients self-reported abuse of alcohol, and alcohol abuse is well known to increase both the risk for and the severity of IPD [24-27].

Occupation may also be a risk factor for acquisition of IPD. Previously we found that welders were at increased risk for IPD with a rate of $22.7 / 100,000$ versus $8.7 / 100,000$ in the general adult population [28]. These findings are extended in this study. There were 53 cases among welders, accounting for $36 \%$ of all construction workers. Exposure to welding fumes promotes lung inflammation and has been shown in animal models to predispose to pneumonia [28]. Several populations with increased exposure to pneumococcal disease such as health care workers and teachers were not overrepresented. Our classification of occupation was done without reference to the National Occupational Classification Statistics Canada 2011 so some of the occupations are likely misclassified. This applies mostly to business and construction categories.

The vast majority (98.9\%) of our patients had one or more comorbid illnesses. Moore et al. found that $76 \%$ of the adults with IPD in the USA had an indication for pneumococcal vaccination [16]. While comorbidities that are risk factors for IPD are well recognized and are for the most part indications for vaccination what is not readily recognized is the concept of risk factor stacking [29]. For example, when smoking is added to diabetes, chronic obstructive lung disease, and chronic heart disease the odds ratio for acquisition of IPD increases from 8.5 to $>40$ [29]. The highest rates of IPD are seen among those who are immunocompromised either by underlying disease or by treatment. In a Toronto study of IPD, $27.8 \%$ of the patients were immunocompromised and those with multiple myeloma had a rate of IPD of $847 / 100,000$, for those with acute leukemia it was 220/100,000, and immunosuppressive therapy led to a rate of 20/100,000 [30]. From 2000 to 2004 we used data on IPD Alberta-wide and cancer registry data and found that compared with a rate of $11 / 100,000$ in the general population patients with multiple myeloma had a rate of IPD of $673 / 100,000$ and rates for those with chronic lymphocytic leukemia, acute myelogenous/acute lymphoblastic leukemia, Hodgkin's disease, and non-Hodgkin's lymphoma were 124; 129; 47; 63/100,000, respectively [31]. We also found a high rate of IPD disease in patients with lung cancer at 143.6/100,000 [31]. A finding unique to the current study is the overrepresentation of patients with hepatitis $\mathrm{C}$. The implication is that hepatitis $\mathrm{C}$ 
should be added to the list of indications for pneumococcal vaccination [32].

From 1935 to present, pneumonia has remained the major manifestation of IPD [33-35]. Meningitis has been the second most common manifestation $[34,35]$ and endocarditis has remained uncommon at about $1 \%[33,35]$. Although the clinical presentation of IPD has not changed much over time, the mortality rate from IPD has declined from $77.5 \%$ in the preantibiotic era to $24.7 \%$ in the early antibiotic era to $16.9 \%$ at the turn of the 21st century and in-hospital mortality remains too high at $15.6 \%$ in our study [33-35]. Austrian and Gold noted in patients with IPD that deaths within the first 5 days seemed not to be influenced by antibiotic therapy [34] and $\mathrm{Yu}$ et al. in the modern era found that $64.5 \%$ of all deaths occurred in the first 3 days [35]. This is in keeping with our observation that most of the life threatening complications occurred on day 1 , an indication that these patients were seriously ill on admission.

Almost half $(43.7 \%)$ of the study population had alteration of mental status. This is much higher than the $11.5 \%$ rate among adults with all-cause pneumonia admitted to Edmonton hospitals [18]. It is also higher than the $23 \%$ value quoted in a review of sepsis associated encephalopathy [36]. The high rate of alteration of mental status in this study is likely accurate because $72 \%$ of the patients with this finding had a Glasgow Coma Score determined and it was abnormal in $92.5 \%$ with $40.6 \%$ having a score of 10 or less. Sepsis associated encephalopathy involves direct cellular damage to the brain [36] and is associated with abnormal electroencephalographic findings [37]. Mortality rates correlate with Glasgow Coma Score with a $63 \%$ mortality for those with a score of $3-8$ [38]. This is an area which clearly needs further study.

Just over $1 \%$ of our patients had new onset stroke following admission to hospital. From 2.2 to $17 \%$ of all strokes have onset during hospitalization for a diagnosis or procedure other than stroke [39]. In a systematic review of trigger factors for ischemic stroke, Guiraud et al. found that infection within the previous week was such a trigger factor with odds ratio of 2.91 (1.41-6) and respiratory tract infection had odds ratio of 2.4 (1.2-4.8) [40]. Hospitalization for infection within 14 days was associated with an increased risk of stroke, OR 8 (1.6-77.3). In a cohort of 5639 patients followed for a median of 12.2 years, 889 developed a stroke within 14 days of hospitalization for some other illness. Twenty-nine of these patients had at least one hospitalization for infection during the preceding 90 days [41]. The infections were mainly of the respiratory or urinary tracts [41].

Pulmonary embolism occurred in $1.3 \%$ of our patients. Investigators from Taiwan found that patients with pneumococcal pneumonia were 1.97 times more likely to have a pulmonary embolus than age and sex matched controls without pneumonia [42]. There are likely several factors that predispose to pulmonary embolism in this population, namely, bed-ridden state for 3 or more days and procoagulant effect of infection [43,44]. In a retrospective review of 1180 medical inpatients, $0.3 \%$ of those at low risk for venous thromboembolism (VTE) developed a pulmonary embolus versus $7.5 \%$ for those at high risk [45]. Thus the overall population of adult patients with IPD is at intermediate risk and should be evaluated for known risk factors for VTE and if present receive prophylaxis [46]. Clearly this is another area in need of further study.

Several of the complications that occurred were pneumonia specific. Thus decortication was necessary because of late stage empyema. Bronchopleural fistula is an uncommon complication that occurs because cavitating pneumonia results in a pneumothorax [47]. Necrotizing pneumococcal pneumonia resulting in cavitation is more common than previously appreciated. With the widespread use of computed tomographic scanning in patients with pneumococcal pneumonia 15/136 (11\%) were found to have such changes [48].

While necrotizing fasciitis is more commonly associated with Group A Streptococcus it does occur with S. pneumoniae [49]. Sixty-five (2.7\%) of our patients had cellulitis of whom 2 had necrotizing fasciitis. Streptococcus pneumoniae is secondary only to the meningococcus as a cause of purpura fulminans [50]; however to 1997 only 43 such cases had been described [51]. In contrast to meningococcemia patients with pneumococcal induced purpura fulminans are often not hypotensive and $51 \%$ to $63 \%$ are asplenic [51]. The mortality rate was $60 \%$ [49]. Our experience of 1 such case among 2435 adult patients suggests that it is uncommon but may be more common than reported in the literature.

Because of a growing literature on the cardiovascular sequelae of sepsis in general [52-57] and pneumococcal infection in particular $[52-56,58]$, we undertook a substudy of cardiovascular complications and risk factors part way through the study (from 2012 to 2014). Acute myocardial infarction is not uncommon following pneumonia with rates ranging from $1.5 \%$ to $15 \%[52,53,58]$. However the $15 \%$ rate was in patients with severe pneumonia [53]. Rhythm disorders are also common, with $12 \%$ having a new diagnosis of cardiac arrhythmia within 90 days of admission for pneumonia [54]. Atrial fibrillation is most common, but other dysrhythmias do occur as in this study where $1.5 \%$ of patients had one or more episodes of asystole and $0.5 \%$ had ventricular tachycardia. A striking finding from our study was that 35\% of patients who had an echocardiogram performed had an ejection fraction of $<50 \%$ indicating systolic dysfunction. Myocardial dysfunction in sepsis has been recognized for some time and this dysfunction may be systolic or diastolic [59-61]. While several factors may play a role in the pathogenesis of cardiovascular complications during the course of IPD the pneumococcus does play a direct role. In both animal models and humans, translocation of $S$. pneumoniae into the myocardium has been observed during pneumococcal sepsis [55]. It has also been shown that pneumolysin causes microscopic lesions in the myocardium [55]. Some interventions may be beneficial; thus aspirin resulted in lower 30-day mortality following pneumonia in one study [56] and vaccination with pneumococcal polysaccharide vaccine was associated with fewer acute coronary syndrome events in another [57].

Table 7 shows selected serotyping data. Fifty-two percent of the isolates had serotypes that are in the current PCV13 formulation. While 59 serotypes were present overall, 28 accounted for $90.3 \%$ of all cases of IPD over the 14 years of the study. The serotype shifts over the course of the study are not shown but it is apparent that more effective control of 
IPD in adults will require new vaccine strategies. Indeed a 15valent $\mathrm{PCV}$ which contains serotypes $22 \mathrm{~F}$ and $33 \mathrm{~F}$ in addition to the PCV-13 serotypes is currently undergoing clinical trials [62]. Serotype $22 \mathrm{~F}$ accounted for $7.2 \%$ of the isolates in our study about the same as the $9.8 \%$ reported Canada-wide from 2011 to 2014 [63]. Serotype 33F accounted for 3\% of isolates in Canada and $1.8 \%$ in our study. The Canada-wide study included children and adults [62].

A strength of this study is the detailed collection of data which allow for a full appreciation of the various epidemiological and clinical factors in IPD. This strength is also a weakness in that in some areas necessary data were not collected. However what the study does do is allow for the development of a standardized data collection instrument which can be used in all future such studies so that comparisons from study to study can be made. There are also several noteworthy limitations to our study. First and foremost, we do not have detailed immunization data for these patients. Second, comorbidities and complications were based on physician records and not necessarily standardized definitions. For example, serial troponins were not collected on all IPD patients nor were echocardiograms done on all patients. Third, biomarkers and measures of inflammatory response were not routinely collected. Fourth, we did not gather data on the few IPD patients that may not have been admitted to hospital. Last, our cohort, though population based, was drawn from the northern half of one province in Canada and some may be concerned that our results are not generalizable to other jurisdictions or nations.

In conclusion, IPD remains a serious infection in adults. Preventative measures to improve vaccination rates especially in the elderly and groups at higher risk that may be harder to reach as shown in this study are needed [63]. Addressing sociodemographic factors that put individuals at higher risk for IPD is also necessary. A standard set of data should be collected so that comparisons can be made from study to study. Future investigations should focus on further elucidation of the cardiovascular effects of IPD and what can be done to ameliorate these effects.

\section{Disclosure}

The funders had no role in the design of the study or data analysis and they have not seen the manuscript.

\section{Conflicts of Interest}

Other than the two research grants mentioned in the Acknowledgments, authors declare no conflicts of interest.

\section{Authors' Contributions}

T. J. Marrie and G. J. Tyrrell designed the study, organized the data collection, and had full access to all of the data in the study. Dean T. Eurich conducted all analyses and had full access to the data. T. J. Marrie, G. J. Tyrrell, Dean T. Eurich, and Sumit R. Majumdar wrote the manuscript. All authors contributed to the interpretation of data, revising the manuscript for intellectual content, and approving the manuscript to be published.

\section{Acknowledgments}

This study was supported by a grant-in-aid from Pfizer, Canada, and Merck Canada Inc. Sumit R. Majumdar holds the Endowed Chair in Patient Health Management supported by the Faculties of Medicine and Dentistry and Pharmacy and Pharmaceutical Sciences at the University of Alberta. Dean T. Eurich is a Canada Research Chair supported by the Government of Canada. The authors wish to thank Ibrahim Quazi and Lilly Yusho for data management and Carol Mangan RN for data collection. They also thank the microbiology staff of hospitals in Northern Alberta for forwarding Streptococcus pneumoniae isolates.

\section{References}

[1] R. Heffron, "The pneumococcus and type incidence in pneumonia," in Pneumonia by R. Heffron, Introduction by Maxwell Finland. The Biology of Pneumococcus by B. White, New Foreword by Robert Austin, R. Heffron, Ed., pp. 18-89, Harvard University Press, Cambridge, Mass, USA, Second Printing, 1979.

[2] C. Rodrigo and W. S. Lim, "The relevance of pneumococcal serotypes," Current Infectious Disease Reports, vol. 16, no. 4, pp. 403-411, 2014.

[3] I. Yildirim, K. M. Shea, and S. I. Pelton, "Pneumococcal disease in the era of pneumococcal conjugate vaccine," Infectious Disease Clinics of North America, vol. 29, no. 4, pp. 679-697, 2015.

[4] M. R. Griffin, Y. Zhu, M. R. Moore, C. G. Whitney, and C. G. Grijalva, "U.S. hospitalizations for pneumonia after a decade of pneumococcal vaccination," New England Journal of Medicine, vol. 369, no. 2, pp. 155-163, 2013.

[5] M. Luján, J. Burgos, M. Gallego et al., "Effects of immunocompromise and comorbidities on pneumococcal serotypes causing invasive respiratory infection in adults: implications for vaccine strategies," Clinical Infectious Diseases, vol. 57, no. 12, pp. 17221730, 2013.

[6] W. Rudnick, Z. Liu, A. Shigayeva et al., "Pneumococcal vaccination programs and the burden of invasive pneumococcal disease in Ontario, Canada, 1995-2011," Vaccine, vol. 31, no. 49, pp. 5863-5871, 2013.

[7] Z. B. Harboe, J. Dalby, D. M. Weinberger et al., "Impact of 13valent pneumococcal conjugate vaccination in invasive pneumococcal disease-incidence and mortality," Clinical Infectious Diseases, vol. 59, pp. 1066-1073, 2014.

[8] Canada Communicable Disease Report, "Case definitions for diseases under national surveillance," Health Canada, vol. 26, supplement 3, article 51, 2000.

[9] R. R. Facklam and A. Washington J, "Streptococcus and related catalase-negative gram-positive cocci," in Manual of Clinical Microbiology, A. Balows, W. J. Hausler Jr., K. L. Herrmann, H. D. Isenberg, and H. J. Shadomy, Eds., pp. 238-257, American Society for Microbiology, Washington, DC, USA, 5th edition, 1991.

[10] "Surveillance and reporting," http://www.ahw.gov.ab.ca/IHDA_ Retrieval.

[11] http://work.alberta.ca/labour/industry-profiles.html. 
[12] A. St. Maurice, W. Schaffner, M. R. Griffin, N. Halasa, and C. G. Grijalva, "Persistent sex disparities in invasive pneumococcal diseases in the conjugate vaccine era," Journal of Infectious Diseases, vol. 214, no. 5, pp. 792-797, 2016.

[13] T. J. Marrie and L. Wu, "Factors influencing in-hospital mortality in community-acquired pneumonia: a prospective study of patients not initially admitted to the ICU," Chest, vol. 127, no. 4, pp. 1260-1270, 2005.

[14] N. Segal, D. Greenberg, R. Dagan, and S. Ben-Shimol, "Disparities in PCV impact between different ethnic populations cohabiting in the same region: a systematic review of the literature," Vaccine, vol. 34, no. 37, pp. 4371-4377, 2016.

[15] T. J. Marrie and J. Q. Huang, "Epidemiology of communityacquired pneumonia in Edmonton, Alberta: an emergency department-based study," Canadian Respiratory Journal, vol. 12, no. 3, pp. 139-142, 2005.

[16] M. R. Moore, R. Link-Gelles, W. Schaffner et al., "Effect of use of 13-valent pneumococcal conjugate vaccine in children on invasive pneumococcal disease in children and adults in the USA: analysis of multisite, population-based surveillance," The Lancet Infectious Diseases, vol. 15, no. 3, pp. 301-309, 2015.

[17] S. Desai, M. E. Policarpio, K. Wong, J. Gubbay, J. Fediurek, and S. Deeks, "The epidemiology of invasive pneumococcal disease in older adults from 2007 to 2014 in Ontario, Canada: a population-based study," CMAJ Open, vol. 4, no. 3, pp. E545E550, 2016.

[18] J. Q. Huang, P. M. Hooper, and T. J. Marrie, "Factors associated with length of stay in hospital for suspected communityacquired pneumonia," Canadian Respiratory Journal, vol. 13, no. 6, pp. 317-324, 2006.

[19] A. Plevneshi, T. Svoboda, I. Armstrong et al., "Population-based surveillance for invasive pneumococcal disease in homeless adults in Toronto," PLoS ONE, vol. 4, no. 9, Article ID e7255, 2009.

[20] A. Mercat, J. Nguyen, and B. Dautzenberg, "An outbreak of pneumococcal pneumonia in two men's shelters," Chest, vol. 99, no. 1, pp. 147-151, 1991.

[21] G. J. Tyrrell, M. Lovgren, Q. Ibrahim et al., "Epidemic of invasive pneumococcal disease, Western Canada, 2005-2009," Emerging Infectious Diseases, vol. 18, no. 5, pp. 733-740, 2012.

[22] Framework for a healthy Alberta, http://www.health.alberta.ca/ documents/Framework-For-Health-2003.pdf.

[23] J. P. Nuorti, J. C. Butler, M. M. Farley et al., "Cigarette smoking and invasive pneumococcal disease," New England Journal of Medicine, vol. 342, no. 10, pp. 681-689, 2000.

[24] L. A. Burman, R. Norrby, and B. Trollfors, "Invasive pneumococcal infections: incidence, predisposing factors, and prognosis," Reviews of Infectious Diseases, vol. 7, no. 2, pp. 133-142, 1985.

[25] J. Fernández-Solá, A. Junque, and R. Estruch, "High alcohol intake as a risk and prognostic factor for community-acquired pneumonia," Archives of Internal Medicine, vol. 155, no. 15, pp. 1649-1654, 1995.

[26] A. De Roux, M. Cavalcanti, M. A. Marcos et al., "Impact of alcohol abuse in the etiology and severity of communityacquired pneumonia," Chest, vol. 129, no. 5, pp. 1219-1225, 2006.

[27] R. Saitz, W. A. Ghali, and M. A. Moskowitz, "The impact of alcohol-related diagnoses on pneumonia outcomes," Archives of Internal Medicine, vol. 157, no. 13, pp. 1446-1452, 1997.

[28] A. Wong, T. J. Marrie, S. Garg, J. D. Kellner, and G. J. Tyrrell, "Welders are at increased risk for invasive pneumococcal disease," International Journal of Infectious Diseases, vol. 14, no. 9, pp. e796-e799, 2010.
[29] D. Curcio, A. Cané, and R. Isturiz, "Redefining risk categories for pneumococcal disease in adults: critical analysis of the evidence," International Journal of Infectious Diseases, vol. 37, pp. 30-35, 2015.

[30] A. Shigayeva, W. Rudnick, K. Green et al., "Invasive pneumococcal disease among immunocompromised persons: implications for vaccination programs," Clinical Infectious Diseases, vol. 62, no. 2, pp. 139-147, 2015.

[31] A. Wong, T. J. Marrie, S. Garg, J. D. Kellner, and G. J. Tyrrell, "Increased risk of invasive pneumococcal disease in haematological and solid-organ malignancies," Epidemiology and Infection, vol. 138, no. 12, pp. 1804-1810, 2010.

[32] C. G. Whitney, M. Moore, T. Pilishvill et al., "Use of 13 valent pneumococcal vaccine and 23 valent pneumococcal polysaccharide vaccine for adults with immunocompromising conditions: recommendations of the Advisory Committee on immunization practices," Morbidity and Mortality Weekly Report (MMWR), vol. 61, no. 40, pp. 816-819, 2012.

[33] R. C. Tilghman and M. Finland, "Clinical significance of bacteremia in pneumococcic pneumonia," Archives of Internal Medicine, vol. 59, no. 4, pp. 602-619, 1937.

[34] R. Austriam and J. Gold, "Pneumococcal bacteremia with especial reference to bacteremic pneumococcal pneumonia," Annals of internal medicine, vol. 60, pp. 759-776, 1964.

[35] V. L. Yu, C. C. C. Chiou, C. Feldman et al., "An international prospective study of pneumococcal bacteremia: correlation with in vitro resistance, antibiotics administered, and clinical outcome," Clinical Infectious Diseases, vol. 37, no. 2, pp. 230-237, 2003.

[36] F. G. Zampieri, M. Park, F. S. Machado, and L. C. P. Azevedo, "Sepsis-associated encephalopathy: not just delirium," Clinics, vol. 66, no. 10, pp. 1825-1831, 2011.

[37] K. Hosokawa, N. Gaspard, F. Su, M. Oddo, J.-L. Vincent, and F. S. I. Taccone, "Clinical neurophysiological assessment of sepsisassociated brain dysfunction: a systematic review," Critical Care, vol. 18, no. 6, article 674, 2014.

[38] L. A. Eidelman, D. Putterman, C. Putterman, and C. L. Sprung, "The spectrum of septic encephalopathy: definitions, etioloqies, and mortalities," Journal of the American Medical Association, vol. 275, no. 6, pp. 470-473, 1996.

[39] E. Cumbler, "In-hospital ischemic stroke," The Neurohospitalist, vol. 5, no. 3, pp. 173-181, 2015.

[40] V. Guiraud, M. B. Amor, J.-L. Mas, and E. Touzé, “Triggers of ischemic stroke: a systematic review," Stroke, vol. 41, no. 11, pp. 2669-2677, 2010.

[41] M. S. V. Elkind, C. L. Carty, E. S. O’Meara et al., "Hospitalization for infection and risk of acute ischemic stroke: the Cardiovascular Health Study," Stroke, vol. 42, no. 7, pp. 1851-1856, 2011.

[42] Y.-G. Chen, T.-Y. Lin, W.-Y. Huang, C.-L. Lin, M.-S. Dai, and C.$\mathrm{H}$. Kao, "Association between pneumococcal pneumonia and venous thromboembolism in hospitalized patients: a nationwide population-based study," Respirology, vol. 20, no. 5, pp. 799-804, 2015.

[43] P. D. Stein, A. Beemath, F. Matta et al., "Clinical characteristics of patients with acute pulmonary embolism: data from PIOPED II," American Journal of Medicine, vol. 120, no. 10, pp. 871-879, 2007.

[44] V. F. Tapson, "Acute pulmonary embolism," New England Journal of Medicine, vol. 358, no. 10, pp. 1037-1052, 2008.

[45] S. Barbar, F. Noventa, V. Rossetto et al., "A risk assessment model for the identification of hospitalized medical patients at risk for 
venous thromboembolism: the Padua Prediction Score," Journal of Thrombosis and Haemostasis, vol. 8, no. 11, pp. 2450-2457, 2010.

[46] S. R. Kahn, W. Lim, A. S. Dunn et al., "Prevention of VTE in nonsurgical patients: Antithrombotic Therapy and Prevention of Thrombosis, 9th ed: American College of Chest Physicians Evidence-Based Clinical Practice Guidelines," Chest, vol. 141, no. 2, supplement, pp. e195S-e226S, 2012.

[47] R. E. Greene, “The radiology of pulmonary infection," in Fishman's Pulmonary Diseases and Disorders, A. P. Fishman, J. A. Elias, J. A. Fishman, M. A. Grippi, R. M. Senior, and A. I. Pack, Eds., chapter 113, pp. 2017-2029, McGraw-Hill, New York, NY, USA, 4th edition, 2008.

[48] A. Pande, S. Nasir, A. M. Rueda et al., "The incidence of necrotizing changes in adults with pneumococcal pneumonia," Clinical Infectious Diseases, vol. 54, no. 1, pp. 10-16, 2012.

[49] M. Dawar, B. Russell, K. McClean, P. N. Levett, G. J. Tyrrell, and J. Irvine, "A case of necrotizing fasciitis due to Streptococcus pneumoniae serotype 5 in Saskatchewan," Canadian Journal of Infectious Diseases and Medical Microbiology, vol. 19, no. 1, pp. 69-71, 2008.

[50] C. Saraceni and D. Schwed-Lustgarten, "Pneumococcal sepsisinduced purpura fulminans in an asplenic adult patient without disseminated intravascular coagulation," American Journal of the Medical Sciences, vol. 346, no. 6, pp. 514-516, 2013.

[51] C. T. Carpenter and A. B. Kaiser, "Purpura fulminans in pneumococcal sepsis: case report and review," Scandinavian Journal of Infectious Diseases, vol. 29, no. 5, pp. 479-483, 1997.

[52] D. M. Musher, A. M. Rueda, A. S. Kaka, and S. M. Mapara, "The association between pneumococcal pneumonia and acute cardiac events," Clinical Infectious Diseases, vol. 45, no. 2, pp. 158-165, 2007.

[53] J. Ramirez, S. Aliberti, M. Mirsaeidi et al., "Acute myocardial infarction in hospitalized patients with community-acquired pneumonia," Clinical Infectious Diseases, vol. 47, no. 2, pp. 182$187,2008$.

[54] N. Soto-Gomez, A. Anzueto, G. W. Waterer, M. I. Restrepo, and E. M. Mortensen, "Pneumonia: an arrhythmogenic disease?" American Journal of Medicine, vol. 126, no. 1, pp. 43-48, 2013.

[55] A. O. Brown, B. Mann, G. Gao et al., "Streptococcus pneumoniae translocates into the myocardium and forms unique microlesions that disrupt cardiac function," PLoS Pathogens, vol. 10, no. 9, Article ID e100438, 2014.

[56] M. Falcone, A. Russo, R. Cangemi et al., "Lower mortality rate in elderly patients with community-onset pneumonia on treatment with aspirin," Journal of the American Heart Association, vol. 4, no. 1, Article ID e001595, 2015.

[57] D. T. Eurich, J. J. Johnstone, J. K. Minhas-Sandhu, T. J. Marrie, and S. R. Majumdar, "Pneumococcal vaccination and risk of acute coronary syndromes in patients with pneumonia: population-based cohort study," Heart, vol. 98, no. 14, pp. 10721077, 2012.

[58] T. W. Perry, M. J. V. Pugh, G. W. Waterer et al., "Incidence of cardiovascular events after hospital admission for pneumonia," American Journal of Medicine, vol. 124, no. 3, pp. 244-251, 2011.

[59] R. Sato, A. Kuriyama, T. Takada, M. Nasu, and S. K. Luthe, "Prevalence and risk factors of sepsis-induced cardiomyopathy. A retrospective cohort study," Medicine, vol. 95, no. 39, Article ID e5031, 2016.

[60] S. Shahul, G. Gulati, M. R. Hacker et al., "Detection of myocardial dysfunction in septic shock: a speckle-tracking echocardiography study," Anesthesia and Analgesia, vol. 121, no. 6, pp. 1547-1554, 2015.

[61] F. Sanfilippo, C. Corredor, N. Fletcher et al., "Diastolic dysfunction and mortality in septic patients: a systematic review and meta-analysis," Intensive Care Medicine, vol. 41, no. 6, pp. 10041013, 2015.

[62] A. R. Golden, H. J. Adam, and G. G. Zhanel, "Invasive Streptococcus pneumoniae in Canada, 2011-2014: characterization of new candidate 15 -valent pneumococcal conjugate vaccine serotypes $22 \mathrm{~F}$ and 33F," Vaccine, vol. 34, no. 23, pp. 2527-2530, 2016.

[63] W. W. Williams, P.-J. Lu, A. O’Halloran et al., "Vaccination coverage among adults, excluding influenza vaccination-United States, 2013," Morbidity and Mortality Weekly Report, vol. 64, no. 4, pp. 95-102, 2015. 


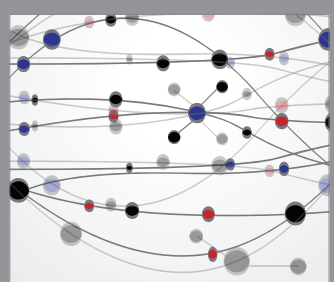

The Scientific World Journal
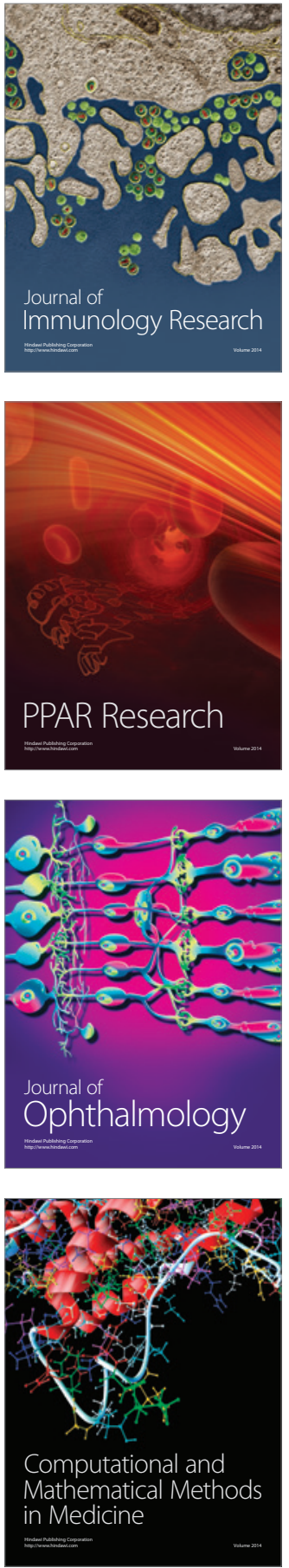

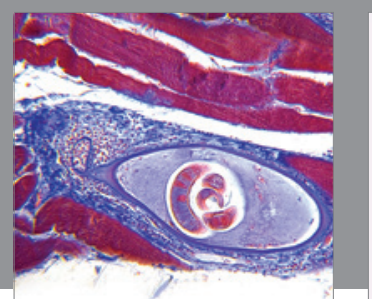

Gastroenterology Research and Practice
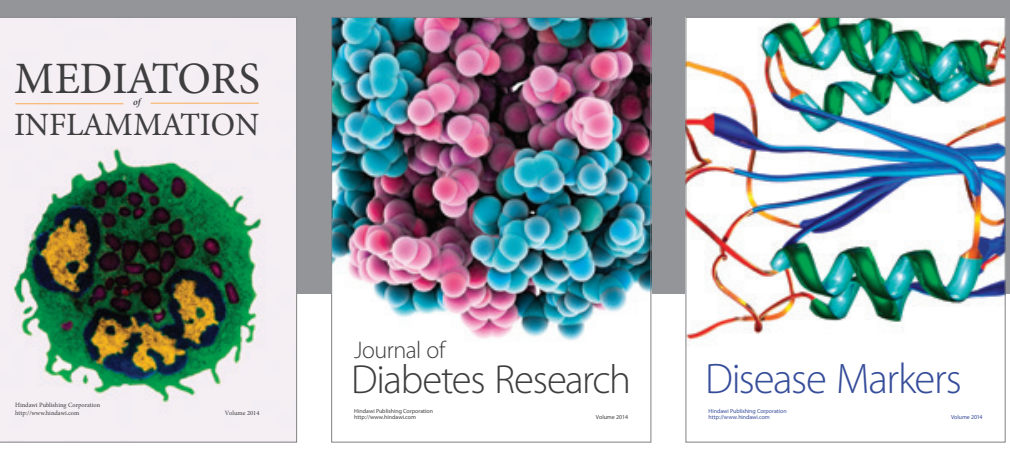

Disease Markers

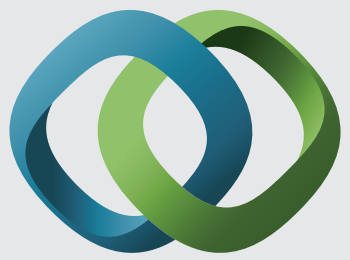

\section{Hindawi}

Submit your manuscripts at

https://www.hindawi.com
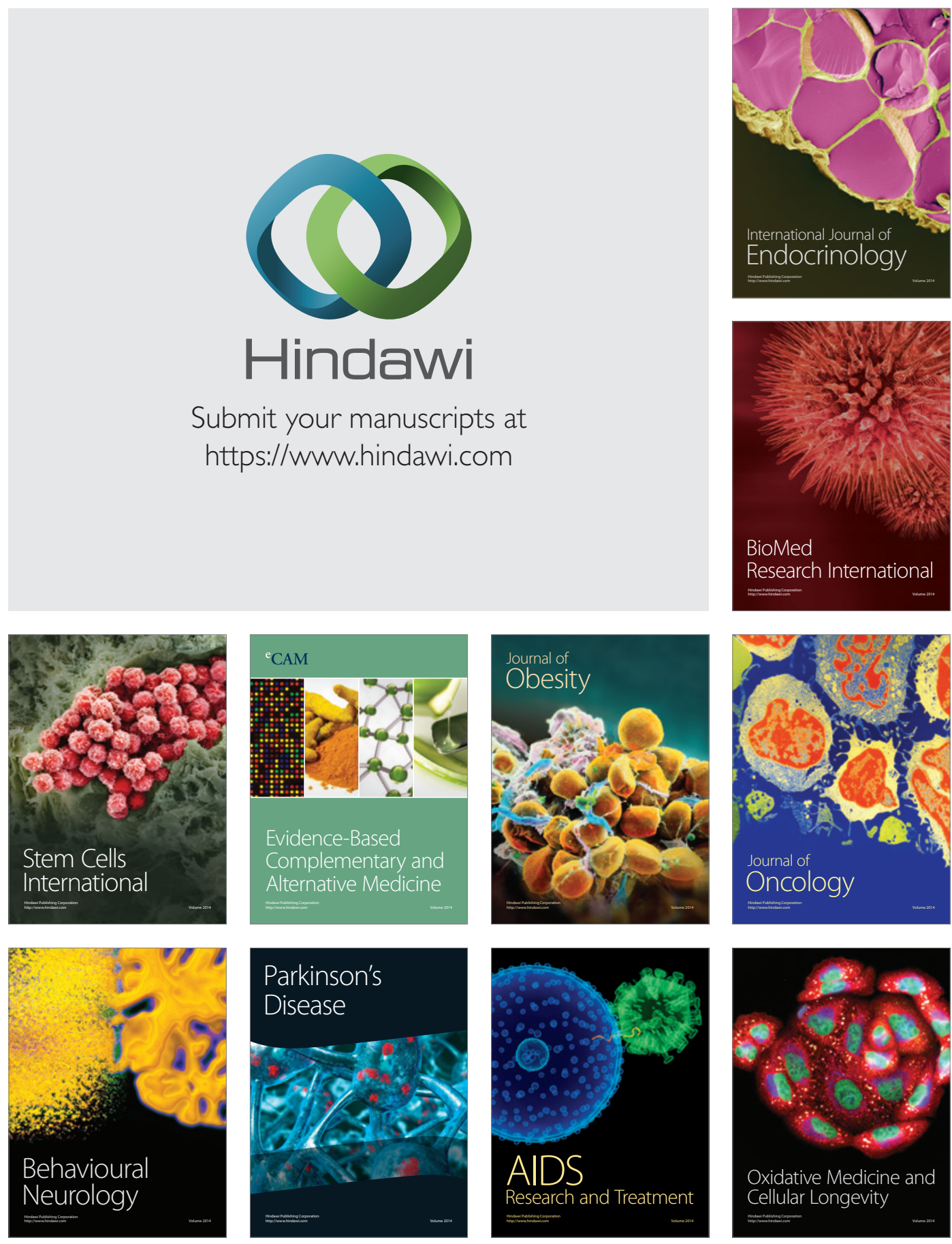